\title{
Isolated acute myocardial infarction of papillary muscles of the heart Clinicopathological study of 9 cases
}

\author{
J. A. Andersen and B. Fischer-Hansen \\ From the Institute of Pathology, Sundby Hospital, DK-2300 Copenhagen S, Denmark
}

Nine cases are reported of isolated acute myocardial infarction of the papillary muscles, revealed by gross histochemical reaction (nitro-BT method) and verified histologically. In 7 cases the infarction was localized to the posterior, in 2 cases to the anterior papillary muscles.

The clinicopathological findings are described and the pathogenesis of this type of acute myocardial infarction is discussed. In our series, papillary muscle dysfunction caused by isolated acute myocardial infarction of papillary muscles led to acute backward failure in 8 out of 9 cases. In 5 of 7 cases with acute myocardial infarction of posterior papillary muscles, electrocardiograms were available, and in 3 of these a third-degree atrioventricular block developed. One case with acute myocardial infarction of anterior papillary muscles developed second-degree atrioventricular block.

In cases with acute backward failure and/or atrioventricular block, isolated acute myocardial infarction of papillary muscles should be considered and, if necropsy is performed, the nitro-BT method is recommended.

It has been shown in experimental studies (Salisbury, Cross, and Rieben, 1963; Bailas, 1965; Mittal et al., 197I) and in clinical and clinicopathological investigations (Arosemena, Moller, and Edwards, 1967; Heikkilä, 1967; Shelburne, Rubinstein, and Gorlin, 1969; Forrester et al., 1971) that the papillary muscles of the left ventricle of the heart are of great importance in maintaining normal haemodynamic conditions.

Papillary muscle dysfunction with mitral incompetence and acute heart failure is caused most often by acute myocardial infarction.

Acute myocardial infarction of papillary muscles is frequently part of a transmural infarct (DePasquale and Burch, 1966; Heikkilä, 1967; Brand, Brown, and Berge, 1969) while isolated acute myocardial infarction of one or both papillary muscles of the left ventricle has rarely been described (Lotti, Zucker, and Bernstein, 1966).

The nitro-BT method was introduced by Nachlas and Shnitka (1963). In an experimental study in dogs, they showed that ligation of a coronary artery produced a pronounced fall in the content of dehydrogenases in the myocardium supplied by the

Received I9 February 1973. artery concerned and that, simultaneously, there was a rise in dehydrogenases in the blood. This depletion of dehydrogenases is considered an irreversible process (Ruegsegger et al., 1959; Strandjord, Thomas, and White, 1959; Hamolsky and Kaplan, 1961).

The undamaged myocardium contains dehydrogenases and a substrate, which are capable of reducing the faintly yellowish tetrazolium salt nitro-BT to dark blue formazan. On the other hand, an area with acute myocardial infarction where the content of dehydrogenases is lower, will not be able to reduce tetrazolium salt, or will reduce it to a slight extent only, and will appear yellowish red, possibly with a slightly bluish tinge.

The nitro-BT method combined with a modified necropsy technique makes it possible and easy to demonstrate even small acute myocardial infarctions of only about 8 hours' duration (Andersen and Fischer-Hansen, 1973).

For these reasons we find it of interest to report on cases with isolated acute myocardial infarction of papillary muscles of the left ventricle, seen in our department since the introduction of the nitro-BT method and, at the same time, we have tried to evaluate the clinical picture and relevance of this type of acute myocardial infarction. 


\section{Subjects and methods}

\section{Necropsy}

The epicardial parts of the coronary arteries were cut open. The degree of atherosclerotic changes of the coronary arteries was estimated as follows: grade $0=$ no changes; grade I = patchy atherosclerotic plaques; grade $\mathbf{2}=$ confluent atherosclerotic plaques. In case of atherosclerotic stenosis it was ascertained whether more or less than 50 per cent of the lumen remained. The occurrence of thrombosis was noted. The heart was weighed, and the outer diameters were measured along the sulcus coronarius and from there vertically to the apex of the heart. The heart was then sliced transversely at intervals of $7.5 \mathrm{~mm}$ from the apex of the heart to the apex of the papillary muscles of the left ventricle. The myocardium was evaluated having regard to acute myocardial infarction and old infarctions (circumscribed fibrosis). In all cases two myocardial slices corresponding to the central third of the ventricles were selected for gross histochemical study. The myocardial slices were rinsed cautiously in running cold water to remove blood, and were then placed for 30 minutes in an incubator at $37^{\circ} \mathrm{C}$ in a preheated solution, consisting of $0.5 \mathrm{mg} / \mathrm{ml}$ nitro-BT in 0.1 M Sørensen phosphate buffer $(p \mathrm{H} 7 \cdot 4)$. Because of the autolysis, $0.1 \mathrm{M}$ solution of sodium succinate and sodium lactate was added as a substrate at a ratio of I: Io to the nitro-BT solution. A quantity of the solution, sufficient to cover the myocardial slices completely, was added, and after 15 minutes the slices were turned in order to avoid constant contact with the bottom of the container. Any lesion of the tissue was avoided. The histochemical reaction was then evaluated macroscopically. The acute myocardial infarctions were all histologically confirmed according to the criteria of Mallory, White, and Salcedo-Salgar (1939). In cases where they were not demonstrated until after application of the nitro-BT method, the following changes were evaluated: granulation and decreased colour intensity of muscle fibres; decrease in cross striation; and nuclear changes (Fig. I and 2) (Andersen and Fischer-Hansen, 1973). The degree of acute stasis and/or oedema $(0,1,2)$ of the lungs was estimated.

In retrospect the case records were examined for a history of heart disease and changes in the electrocardicgram, auscultation of the heart, blood pressure, and coronary enzymes (SGOT, SLDH, and SCPK) during the period of acute myocardial infarction.

\section{Results}

The results appear in the Table. In 7 out of 9 cases the posterior papillary muscle was involved; in no case were both pupillary muscles involved. In only one case could the acute myocardial infarction be seen before application of the nitro-BT method.
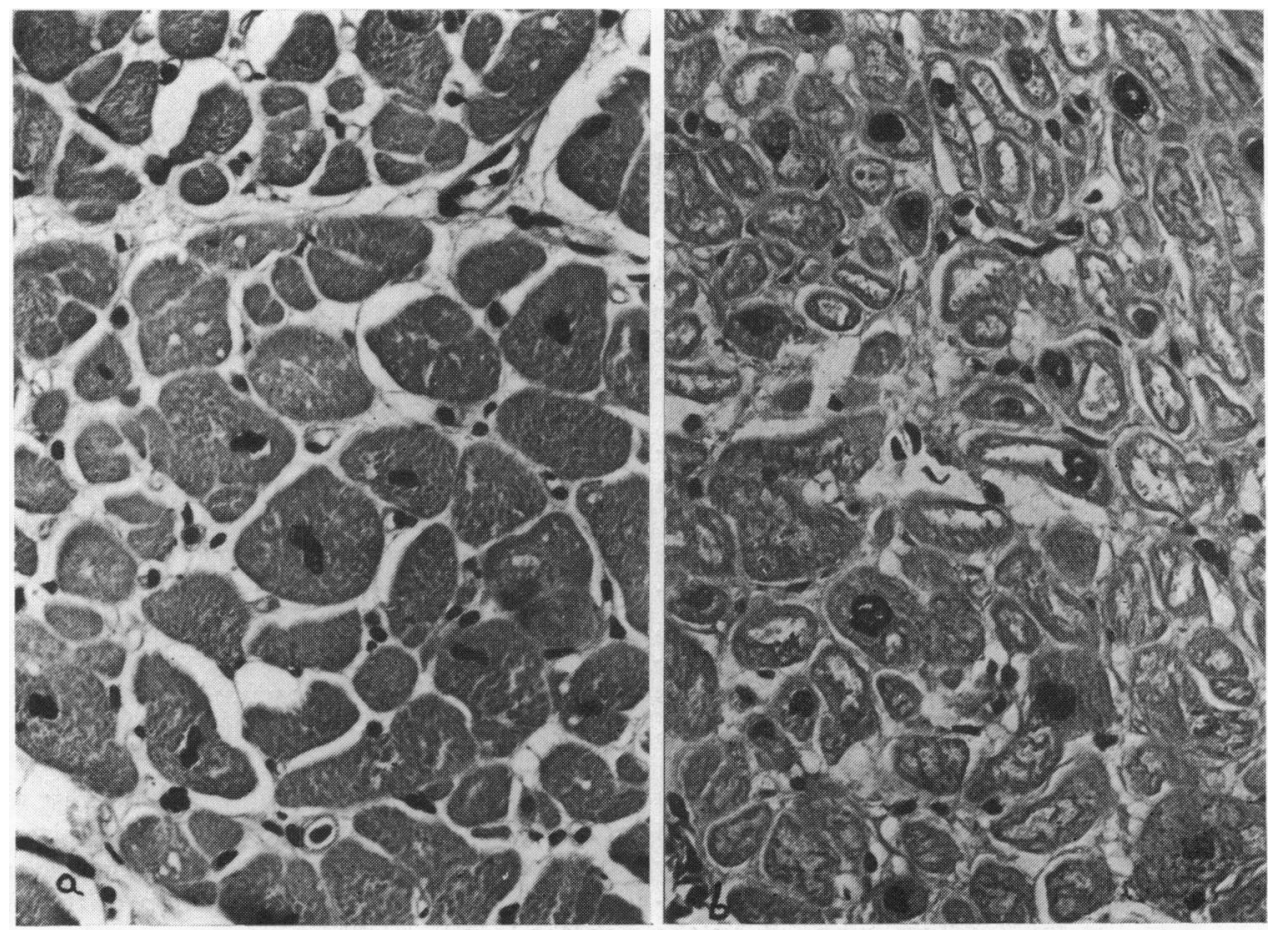

FIG. I Cross-section of myocardial fibres in non-infarcted (a) and infarcted (b) areas of papillary muscle. Note the difference in intensity of staining and the nuclear changes. ( $X I 2$. 
Five patients had severe diffuse atherosclerotic changes (grade 2) in the coronary arteries, and of these, 4 had severe atherosclerotic stenosis (more than $50 \%$ ). Four patients had slight diffuse atherosclerotic changes (grade I), in one case with severe, and in another case with slight atherosclerotic stenosis (less than 50\%). No thrombosis was diagnosed. In 4 cases there was circumscribed fibrosis of the myocardium. In all cases histological examination showed changes compatible with recent infarction according to the criteria mentioned above (Fig. I and 2).

Eight patients had severe acute congestion and/or oedema of the lungs, and in the remaining case the changes could not be correctly estimated because of severe pneumonia and partial infarction of the lung.

Auscultation of the heart was recorded in 4 cases.

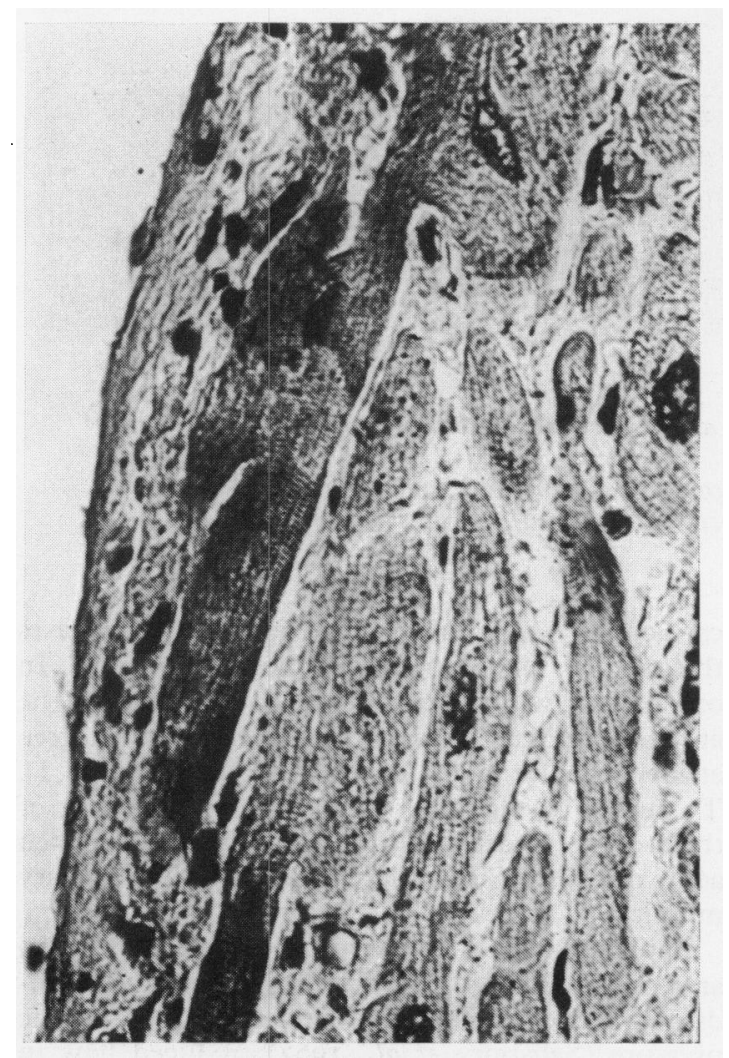

FIG. 2 Longitudinally cut myocardial fibres of papillary muscle from subendocardial area. Note the changes in intensity of staining and in cross-striation from the most subendocardial, typically non-infarcted, fibres to the subjacent infarcted fibres. The varying large granules are remnants of formazan from the macroscopical study. $(\times 42$.)
In one of these a rough systolic murmur developed during the terminal illness.

In 2 cases the coronary enzymes had been investigated and a significant rise in titre was found. Isoenzyme values were not available.

Electrocardiograms were available in 6 patients.

Case I (leads I-III) Died 45 minutes after admission. Electrocardiogram on admission showed left bundle-branch block and $P Q \quad 0.22$ sec. Ten minutes later in addition to left bundle-branch block atrial fibrillation had developed. The electrocardiogram Io minutes before death showed third-degree atrioventricular block.

Case 3 (leads I-III, VI, 4, 6) Died 31 days after admission. Electrocardiograms recorded 3I, 8, and 2 days before death showed increasing ST depression in $\mathrm{V}_{4}$, and unchanged isoelectric $\mathrm{T}$ waves (Fig. 3). The electrocardiograms recorded 8 and 2 days before death showed multifocal ventricular extrasystoles.

Case 4 (leads I-III, VI-6) Died 3 days after admission. Electrocardiogram recorded one day before death showed ventricular and supraventricular extra systoles. A QIII was unchanged from recordings 6 months previously.

Case 5 (leads I-III, VI-6, aVR, aVL, aVF) Died I $\frac{1}{2}$ hours after admission. On admission electrocardiogram showed left bundle-branch block and, 35 minutes later, second-degree atrioventricular block (Mobitz type I) (Fig. 4).

Case 6 (leads I-III, VI, 4, 6) Died II hours after admission. The first electrocardiogram showed third-degree atrioventricular block, QRS duration $0 \cdot$ I I sec, and bradycardia (20/min). The last electrocardiogram showed third-degree atrioventricular block, QRS duration 0.16 sec, and ST elevation in leads I and II.

Case 8 (leads I-III, VI-6) Died 3 hours after admission. Electrocardiogram on admission was unchanged from recordings $2 \frac{1}{2}$ months earlier: QIII, QS in V4, ST elevation in V2, ST depression in V6, and negative $T$ waves in leads $I$ and V6. Electrocardiogram recorded 20 minutes before death showed third-degree atrioventricular block (Fig. 5).

\section{Discussion}

Isolated acute myocardial infarction of papillary muscles has been reported on rare occasions only. For example, Lotti et al. (1966) found only one case out of 3300 consecutive necropsies.

Four of our 9 cases are from a consecutive series 


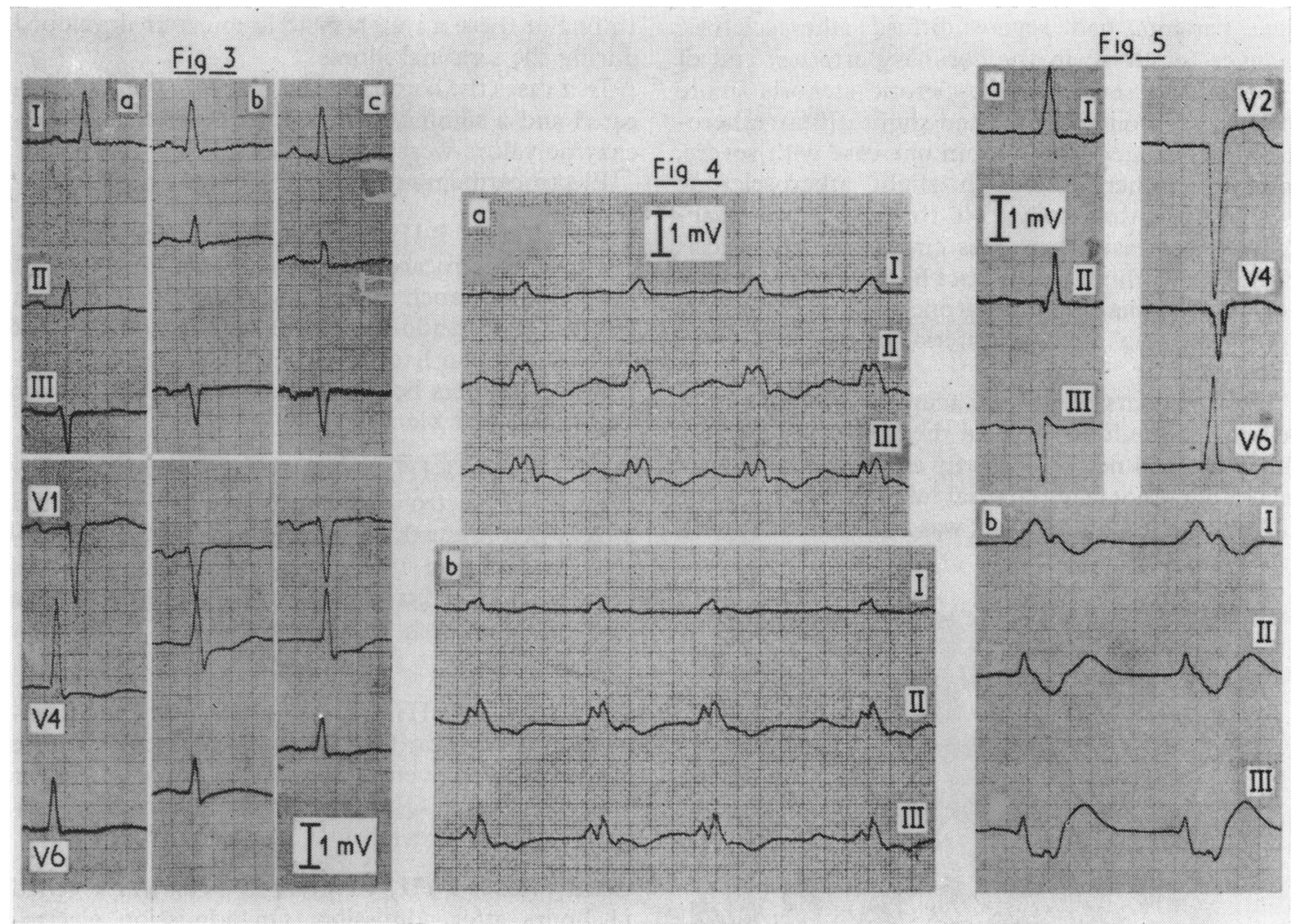

FI G. 3 Electrocardiograms from Case $3(a),(b)$, and (c) are recorded 31,8 , and 2 days, respectively, before death.

FIG. 4 Electrocardiograms from Case 5. (a) Recorded on admission, and (b) 35 minutes later. FIG. 5 Electrocardiograms from Case 8 . (a) Recorded $2 \frac{1}{2}$ months earlier, and (b) recorded 20 minutes before death.

of roo unselected necropsies (Andersen and FischerHansen, 1973), while the other 5 cases were found by applying the nitro-BT method in selected cases. In only one case could acute myocardial infarction be demonstrated by conventional gross evaluation and consequently the high frequency of cases of acute myocardial infarction of papillary muscles found by us is a result of the application of the nitro-BT method. In none of the cases was the diagnosis suspected clinically and, when the case records were reviewed retrospectively, we did not find electrocardiographic abnormalities characteristic of the type of infarct as described by Philips, Burch, and DePasquale (1963). In only one case did a systolic murmur develop during the terminal course. On the other hand, the importance of papillary muscle dysfunction is quite evident in our series, 8 patients presenting signs of severe backward failure. In 5 of the 7 patients with acute myocardial infarction of posterior papillary muscle, the electro- cardiogram was available, and in 3 of these cases third-degree atrioventricular block developed. In one patient with acute myocardial infarction of the anterior papillary muscle, however, second-degree atrioventricular block developed (Mobitz type I). To our knowledge, there are no previous reports of third-degree heart block in connexion with isolated acute myocardial infarction of the posterior papillary muscle.

Papillary muscle forms part of the subendocardial area (Estes et al., 1966). The following factors predispose to ischaemia of this area: increased diastolic pressure (Salisbury et al., 1963); reduced flow in coronary arteries depending either on local factors in the vessels (Ishihara et al., I967), or on generalized hypotension (Mauney, Ebert, and Sabiston, 1970); and muscular hypertrophy (Arosemena et al., 1967).

The importance of increased diastolic pressure cannot be assessed in our series, since no pressure 
TABLE History of heart disease and necropsy findings in 9 cases of isolated acute myocardial infarction of papillary muscle of left ventricle

\begin{tabular}{|c|c|c|c|c|c|c|c|c|}
\hline No. & Age/sex & $\begin{array}{l}\text { Papillary } \\
\text { muscle } \\
\text { involved }\end{array}$ & $\begin{array}{l}\text { Weight }(\mathrm{g}) \\
\text { and outer } \\
\text { measurement } \\
\text { of heart }(\mathrm{cm})\end{array}$ & $\begin{array}{l}\text { Atherosclerosis } \\
\text { of coronary } \\
\text { arteries } \\
(0, I, 2)\end{array}$ & $\begin{array}{l}\text { History } \\
\text { of heart } \\
\text { disease } \\
(y r)\end{array}$ & $\begin{array}{l}\text { Blood } \\
\text { pressure } \\
(\mathrm{mmHg})\end{array}$ & $\begin{array}{l}\text { Oedema } \\
\text { and/or } \\
\text { acute stasis } \\
\text { of lungs } \\
(0, I, 2)\end{array}$ & $\begin{array}{l}\text { Other essential necropsy } \\
\text { findings }\end{array}$ \\
\hline I & $74 \mathrm{M}$ & Posterior & $\begin{array}{l}560 \\
11 \times I I \cdot 5\end{array}$ & 2 & ? & $100 /-$ & 2 & $\begin{array}{l}\text { Severe valvular aortic } \\
\text { stenosis }\end{array}$ \\
\hline 2 & $83 \mathrm{M}$ & Posterior & $\begin{array}{l}465 \\
15 \times 10\end{array}$ & $\mathbf{I}$ & - & $70 / 40$ & $\mathbf{I}$ & Gastrointestinal haemorrhage \\
\hline 3 & $80 \mathrm{~F}$ & Posterior & $\begin{array}{l}450 \\
\text { II } \times 10\end{array}$ & 2 & 一 & $?$ & $\mathbf{I}$ & $\begin{array}{l}\text { Mammary carcinoma with } \\
\text { metastasis }\end{array}$ \\
\hline 4 & $81 \mathrm{~F}$ & Anterior & $\begin{array}{l}365 \\
10.5 \times 11\end{array}$ & I & $\mathbf{I}$ & $80 /-$ & - & $\begin{array}{l}\text { Severe pneumonia and partial } \\
\text { infarction of lung }\end{array}$ \\
\hline 5 & $62 M$ & Anterior & $\begin{array}{l}525 \\
10.5 \times 10.5\end{array}$ & 2 & ro & $70 /-$ & 2 & \\
\hline 6 & $42 \mathrm{~F}$ & Posterior & $\begin{array}{l}410 \\
\text { II. } 5 \times 9.5\end{array}$ & $\mathbf{I}$ & $?$ & $\begin{array}{l}\text { Unobtain- } \\
\text { able }\end{array}$ & 2 & Acute pancreatitis \\
\hline 7 & $38 \mathrm{~F}$ & Posterior & $\begin{array}{l}370 \\
9.5 \times 9\end{array}$ & 2 & $\frac{1}{2}$ & $?$ & 2 & $\begin{array}{l}\text { Diabetic nephropathy } \\
\text { (uraemia) }\end{array}$ \\
\hline 8 & $66 \mathrm{~F}$ & Posterior & $\begin{array}{l}640 \\
13 \times 12\end{array}$ & $\mathbf{I}$ & 32 & $\begin{array}{l}\text { Unobtain- } \\
\text { able }\end{array}$ & 2 & $\begin{array}{l}\text { Moderate valvular aortic } \\
\text { stenosis; severe pneumonia }\end{array}$ \\
\hline 9 & $88 M$ & Posterior & $\begin{array}{l}320 \\
10 \times 9\end{array}$ & 2 & $?$ & $?$ & 2 & $\begin{array}{l}\text { Moderate valvular aortic } \\
\text { stenosis; carcinoma of } \\
\text { urinary bladder; orchitis }\end{array}$ \\
\hline
\end{tabular}

measurements are available. In 4 patients pronounced atherosclerotic vascular changes were found, and in 3 there was long-standing generalized hypotension. In 7 cases varying degrees of muscular hypertrophy of the left ventricle were present.

It is worth noting that 3 of our patients had moderate or severe isolated valvular aortic stenosis.

Our material shows that papillary muscle dysfunction depending on isolated acute myocardial infarction of papillary muscles will produce acute backward failure and, furthermore, very often atrioventricular block. In cases of acute backward failure and/or atrioventricular block, therefore, the possibility of isolated acute myocardial infarction of papillary muscles must be taken into consideration and, in the event of necropsy, application of the nitro-BT method is recommended.

\section{References}

Andersen, J. A., and Fischer-Hansen, B. (1973). The value of the nitro-BT method in fresh myocardial infarction. Frequency and location of fresh myocardial infarction in a consecutive series of autopsies. American Heart fournal, 85,611 .

Arosemena, E., Moller, J. H., and Edwards, J. E. (1967). Scarring of the papillary muscles in left ventricular hypertrophy. American Heart fournal, 74, 446.

Bailas, N. (1965). Functional mitral insufficiency in acute myocardial ischemia. American fournal of Cardiology, 16, 807.

Brand, F. R., Brown, A. L., and Berge, K. G. (1969). Histology of papillary muscles of the left ventricle in myocardial infarction. American Heart fournal, 77, 26.
DePasquale, N. P., and Burch, G. E. (1966). The necropsy incidence of gross scars or acute infarction of the papillary muscles of the left ventricle. American fournal of Cardiology, 17, 169.

Estes, E. H., Dalton, F. M., Entman, M. L., Dixon, H. B., and Hackel, D. B. (1966). The anatomy and blood supply of the papillary muscles of the left ventricle. American Heart fournal, 71, 356.

Forrester, J. S., Diamond, G., Freedman, S., Allen, H.N., Parmley, W. W., Matloff, J., and Swan, H. J. C. (197I). Silent mitral insufficiency in acute myocardial infarction. Circulation, 44, 877.

Hamolsky, M. W., and Kaplan, N. O. (196I). Measurements of enzymes in the diagnosis of acute myocardial infarction. Circulation, 23, 102.

Heikkilä, J. (1967). Mitral incompetence as a complication of acute myocardial infarction. Acta Medica Scandinavica, 182, Suppl. 475.

Ishihara, Y., Lyon, L. D., Love, W. D., and Smith, R. O. (1967). Production of subendocardial ischemia by selective coronary arterial hypotension. Circulation (Suppl. II), 36, 149.

Lotti, L., Zucker, I. R., and Bernstein, A. (1966). Clinical and pathologic observations in acute papillary muscle infarction. Vascular Diseases, 3, 168.

Mittal, A. K., Langston, M., Cohn, K. E., Selzer, A., and Kerth, W. J. (197I). Combined papillary muscle and left ventricular wall dysfunction as a cause of mitral regurgitation. Circulation, 44, I74.

Mallory, G. K., White, P. D., and Salcedo-Salgar, J. (1939). The speed of healing of myocardial infarction: a study of the pathologic anatomy in seventy-two cases. American Heart fournal, 18, 647.

Mauney, F. M., Ebert, P. A., and Sabiston, D. C. (1970). Postoperative myocardial infarctions: a study of predisposing factors, diagnosis and mortality in a high risk group of surgical patients. Annals of Surgery, I72, 497. 
Nachlas, M. M., and Shnitka, T. K. (1963). Macroscopic identification of early myocardial infarcts by alterations in dehydrogenase activity. American fournal of Pathology, 42, 379.

Philips, J. H., Burch, G. E., and DePasquale, N. P. (I963). The syndrome of papillary muscle dysfunction. Annals of Internal Medicine, 59, 508.

Ruegsegger, P., Nydick, I., Freiman, A., and LaDue, J. S. (1959). Serum activity patterns of glutamic oxaloacetic transaminase, glutamic pyruvic transaminase and lactic dehydrogenase following graded myocardial infarction in dogs. Circulation Research, 7, 4.

Salisbury, P. F., Cross, C. E., and Rieben, P. A. (1963). Acute ischemia of inner layers of ventricular wall. American Heart fournal, 66, 650.

Shelburne, J. C., Rubinstein, D., and Gorlin, R. (1969). A reappraisal of papillary muscle dysfunction. American Fournal of Medicine, 46, 862.

Strandjord, P. E., Thomas, K. E., and White, L. P. (1959). Studies on isocitric and lactic dehydrogenases in experimental myocardial infarction. Fournal of Clinical Investigation, 38, $211 \mathrm{I}$.

Requests for reprints to Dr. J. A. Andersen, Department of Pathology, Sundby Hospital, Italiensvej I, 2300 Copenhagen S, Denmark. 